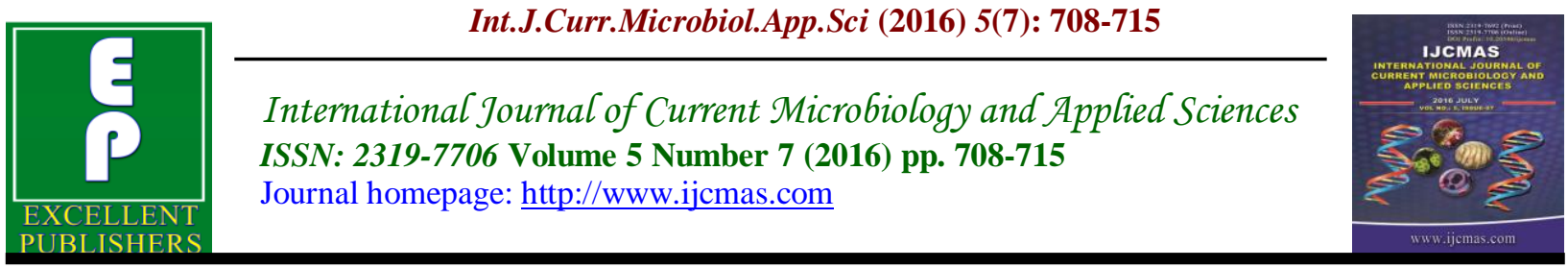

Original Research Article

http://dx.doi.org/10.20546/ijcmas.2016.507.081

\title{
Prevalence and Multidrug Antimicrobial Susceptibility of Bacteria Isolates Obtained from Surgical Site in Nigeria
}

\author{
I. Ehiaghe Joy*, F.A. Eghiaghe, R.A.U. Nwobu and O. Nwiyi Paul \\ ${ }^{1}$ Lahor Research and Medical Diagnostic Center, Benin. \\ Eghiaghe F.A. \\ ${ }^{2}$ Department of Hematology, College of Health Science, Igbinedion University, Okada, Nigeria \\ ${ }^{3}$ Department of Medical Laboratory Science, Nnamdi Azikiwe University, Awka, Nigeria \\ ${ }^{4}$ Department of Veterinary Microbiology and Parasitology College of Veterinary Medicine, \\ Michael Okpara University of Agriculture Umudike, Nigeria \\ *Corresponding author
}

Keywords

Prevalence, bacteria, antibiotics, teaching hospital.

Article Info

Accepted:

22 June 2016

Available Online:

10 July 2016

\section{A B S T R A C T}

The study was aimed at evaluating the prevalence and multidrug resistance of bacteria isolates recovered from patients with clinically diagnosed postoperative surgical wound infections. Bacteria isolates were recovered from 362 swabs specimens of patients from University of Benin Teaching Hospital(UBTH) and Nnamdi Azikiwe University Teaching Hospital (NAUTH). A cross sectional study was adopted for this research and the specimens were obtained using the randomized sampling method and samples were cultured on Blood and MacConkey agar media and incubated aerobically and anaerobically for 48 hours. Phenotypic characterizations of bacteria isolates from both locations were confirmed molecularly to be $(100 \%)$. These bacteria isolates were then subjected to Antibiotic susceptibility testing by Kirby-Bauer disk diffusion technique on Mueller-Hinton agar. The result shows that one hundred and twenty two (33.7\%) surgical wound bacteria isolates which included four different genera ( $P$. aeruginosa, $E$. coli, $P$. mirabilis and $S$. aureus) were recovered from postoperative surgical wound swab specimens. Prevalence of multidrug resistant isolates were found to be drastically high in both locations $(\mathrm{UBTH}=78 \%, \mathrm{NAUTH}=85 \% ; \mathrm{OR}=1.182 ; \mathrm{P}$ value $=1.000)$. There were no significant differences $(\mathrm{P}>0.05)$ in the isolation of pathogens with respect to locations. Isolates exhibited highest resistance to Augmentin, Cefuroxime and cefixime from both locations and least resistance to Imipenem among the antibiotics tested against Gram negative isolates. The most predominant isolates from both locations were $P$. aeruginosa $(\mathrm{UBTH}=60 \%$; NAUTH $=36 \%)$ and $E$. coli $(\mathrm{UBTH}=34 \%$; $\mathrm{NAUTH}=52 \%$ ). They exhibited high preponderance of multidrug resistance in both locations ( $P$. aeruginosa, UBTH (90\%), NAUTH (92\%); E. coli, UBTH (70\%), NAUTH (95\%). Also UBTH registered $78 \%$ multidrug resistance while NAUTH had $85 \%$. Surgical wound infections with resistant bacteria constitute a significance cause of morbidity in the study area. Findings in this study justify the need to strengthen infection control and treatment should be based on current laboratory susceptibility test results, and greater collaboration between microbiologists and clinicians to prevent the spread of multidrug resistant bacteria 


\section{Introduction}

Surgical site infection (SSI) is defined as an infection occurring within 30 days after a surgical operation (or within 1 year if an implant is left in place after surgical procedure) and affecting either incision or deep tissues at the operation site (ManGram et al., 1999). Surgical site infections depend on the host susceptibility, condition of the wound, and the amount and type of microbial contamination (Oni et al., 2006). Surgical site infection (SSL) is the most common nosocomial infection in surgical patients, accounting for $39.9 \%$ of all infections. It is a significant source of post operative morbidity, resulting in longer hospitalization, increased cost and increased incidence of post-operative mortality (Mohammed et al., 2013). As most infections are the result of wound contamination by endogenous bacteria from the patient's skin, mucous membrane or hollow viscera, the concept of using a physical barrier to cover the out edges of the wound has been visited by surgeons many times over the past half century.

Infection may be defined as invasion and multiplication of microorganisms in body tissues, which maybe clinically in apparent or result in local cellular in-jury because of competitive metabolite intracellular replication or antigen-antibody response. This series of events leads to progressive tissue destruction and eventual death of the host if left unchecked (Saunders, 2005).

On the basis of degree of microbial contamination, surgical site infections can be classified into four major groups: Clean site wounds, clean contaminated wounds, contaminated wounds, dirty or infected wounds (Anaya et al.,2006). The development of an infection is influenced largely by the virulence of the organism and immunological status of the patient, when microorganisms are present to a degree of $10^{5}$ per Gram of tissue, an infection is likely to be present. However, any purulent discharge from a closed surgical incision, together with signs of inflammation of the surrounding tissues should be considered as wound infection, irrespective of whether microorganisms had been cultured from it. Quantitatively, wounds harboring bacteria that exceeds $10^{5}$ colony forming unit per Gram are considered infected wounds (Heggars, 2003). Gram negative bacteria can contaminate skin wounds of the groin and perinea areas. The contaminating pathogens in gastro intestinal surgeries are the intrinsic bowel flora which includes Gram-negative bacilli and Gram-positive microbes, including enterococci and anaerobic organisms. Bacterial isolates colonizing surgical wounds vary in their carriage of genes encoding antibiotic resistance (Yah $e t$ al., 2004).

Thus, the routine use of antimicrobial agents in both human and veterinary medicine has resulted in wide spread antibiotic resistance genes especially within the Gram negative bacteria (Enabulele et al., 2006). With the presence of antibiotic selective pressure, these resistant bacteria species tend to persist, enabling the organism to cause extra infections such as septicaemia (Prescott et al., 2008).

Most bacteria have developed resistance to antibiotics through various mechanisms which includes; production of enzymes that inactivate the antibiotics, efflux pumping machinery on the cell membrane, modification of drug structure, loss of porin proteins and acquisition of genes that harbor resistant plasmids. This has brought about the need for the development of new antibiotics that will be more effective in chemotherapy (Lee et al., 2000; Tenover, 2006). 
Few studies conducted in Africa have also reported varying magnitude of SSI depending on procedures and specialties in which it was performed. In one prospective multicenter study done at large hospitals in Lagos, Nigeria, low prevalence rate of surgical site infections (9.6\%) was reported among women who underwent caesarian section. The reason for this low prevalence was inferred to possibly be due to exclusion of cases with sub umbilical midline incision (Ezechi et al., 2009). Nejad et al., 2011 reported the prevalence rate of $(34.4 \%)$ for E. coli from surgical wounds infections.

However, in other studies, Aisha, et al. (2013) and Dalhatu et al. (2014) reported $P$. aeruginosa as the most recovered from post operative surgical wounds despite the site of infection and location of specimens due to its high survival characteristics in hospital environment. It is known to rank second among nosocomial pathogens isolated from hospitals, often contaminating hospital equipments such as wound dressing sinks and other surgical apparatus and even antibiotic resistant strains can survive in supposedly sterile equipments used in the hospitals making it a dangerous nosocomial pathogen widely distributed in the hospital environments where they are particularly difficult to eradicate (Masaadeh et al., 2009).

In this study, the Knowledge of types of bacterial pathogens and antimicrobial resistant pattern can optimize treatment and decrease disease morbidity and mortality rates of surgical wound infections. Also, bacterial resistance can result in complicated cases of surgical wound infection such as Septicemia especially in immunocompromised patients leading to prolongation of therapy and even therapeutic failures.
Getting to know the drug resistance strategies possessed by etiologic agents of surgical site infections will greatly improve chemotherapeutic approaches in the treatment of wound infections worldwide.

\section{Materials and Methods}

A total of 362 clinical wound swabs samples were collected from post operative hospitalized surgical patients. One hundred and eighty one of the samples were from UBTH in Edo state while one hundred and eighty one was from NAUTH in Anambra state.

\section{Sample collection}

Random samplings of patients with post operative surgical wounds were used in this study. An informed consent form was signed before sample collection. Samples were only collected from patients before surgical wound dressing. Two swabs sample were collected using sterile swab sticks from each patient and placed inside an Amies transport medium. All collections were done under strict aseptic conditions. Specimens were transported immediately to the Medical microbiology Department of Lahor Research Laboratories and Medical Centre, Benin City, Edo state for analysis within 4 hours of sample collection.

\section{Bacteriological analysis}

The wound swab specimens were inoculated on Blood agar, MacConkey agar, Nutrient agar, and Mannitol salt agar plates and were incubated aerobically and anaerobically at $37^{0} \mathrm{C}$ for 24 hours. Duplicate blood agar plates were incubated anaerobically at $37^{\circ} \mathrm{C}$ for 24 hours. Bacterial isolates were phenotypically identified morphologically and biochemically (Cowan and steel, and Cheesbrough, 2000). 


\section{Microscopic Examination, Isolation and} identification

Phenotypic characterization of the bacterial isolates was as described (Cheesbrough, 2000). The colonies on the MacConkey agar were classified into lactose and non-lactose fermenting colonies. The non-lactose fermenting colonies and lactose fermenting colonies were further subjected to conventional biochemical tests such as citrate utilization, urea production, indole production, Oxidase test, motility test, sugar fermentation (maltose, sucrose and mannitol) test (Cowan and Steel, 1974). The smear was made from the wound swab specimens after culture, and staining was by Gram technique, before subjecting the smear to oil emulsion and examination at X100 objectives for bacterial morphology.

\section{Antibiotics Susceptibility Testing}

Antimicrobial susceptibility testing was carried out on each isolates by the disc diffusion method using the Kirby-Bauer disc diffusion method in accordance with the National Committee for Clinical Laboratory Standards (NCCL, 2003) guideline to evaluate the sensitivity of the test organisms to the various antibiotics. The following antibiotics were use: Ceftazidime (Caz

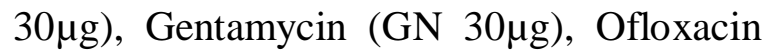

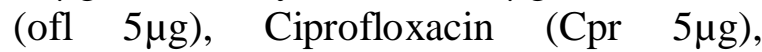
Erythromycin (Ery 10ug), Imipenem (lmp 10ug), Oxacillin (oxa, 1ug,), Cefuroxime (Crx 30ug), Cefixime (CXM 5ug), and Augmentin (Aug, 30ug) (Oxide). The discs were procured from Oxoid Ltd, Wade Road, Basingstoke, and Hants, RG24 8PW, UK.

After incubation, diameters of zones of inhibition were measured to the nearest millimeter using a transparent meter rule. The clinical isolates diameter zones were compared with reference control organism (E.coli ATCC 25922, P.aeruginosa ATCC 27853 and S.aureus ATCC 6538) obtained from Lahor Research Laboratories, Benin city, Edo State.

\section{Results and Discussions}

A total of three hundred and sixty two (362) post operative wound swabs specimens from hospitalized patients at UBTH and NAUTH were analyzed. A total of 122 clinical bacterial isolates were isolated from both locations, with an overall prevalence of $33.7 \%$. Although this is lower than an earlier report of 39.9\% (Mohammed et al., 2013), it is still high when compared to the result of Ezechi et al.,(2009) who reported a prevalence rate of $9.6 \%$.

However, World Health Organization in 2011 gave a prevalence rate of $5-34 \%$ of SSI and this is in line with the result of this study. One hundred and eighty one (181) patients from each location were investigated and a total of $122(33.7 \%)$ of all patients studied had wound infection. A high prevalence $(39.8 \%)$ of wound infection was recorded among patients in NAUTH when compare with the study in UBTH was $(27.6 \%)$, thus, the results obtain is lower than that of Reiye, et al. (2014) who reported a prevalence rate of $75 \%$ in surgical wounds, but higher than that of (Sule et al., 2002) who reported a prevalence rate of $(11 \%)$.

$P$. aureginosa was the more predominant in UBTH followed by E. coli, $S$ aeures and $P$. mirabilis with prevalence of $60 \%, 34 \%, 6 \%$ and $0 \%$ while E. coli was dominant in NAUTH followed by $P$. aeruginosa, $S$. aureus and $P$. mirabilis with prevalence of $52 \%, 36 \%, 8.3 \%$ and $2.8 \%$, respectively (Table2). 
Table.1 Prevalence of surgical wound infection in UBTH and NAUTH

\begin{tabular}{lllll}
\hline $\begin{array}{l}\text { Variable } \\
\text { Location }\end{array}$ & $\mathrm{N}$ & No. infected $(\%)$ & OR & $95 \% \mathrm{CI}$ \\
\hline UBTH & 181 & $50(27.6)$ & 0.569 & $0.365,0.890$ \\
NAUTH & 181 & $72(39.8)$ & 1.756 & $1.120,2.798$ \\
TOTAL & 362 & $12233.7)$ & & \\
\hline
\end{tabular}

$\mathrm{N}=$ Number of sample examined; $\mathrm{OR}=$ Odd ratio; $\mathrm{Cl}=$ confidence interval

Table.2 Distribution of etiologic agents of wound infection

\begin{tabular}{llllll}
\hline Variable & $\mathrm{N}$ & $\begin{array}{l}\text { E. coli } \\
\mathrm{N}(\%)\end{array}$ & $\begin{array}{l}\text { P. aeruginoa } \\
\mathrm{N}(\%)\end{array}$ & $\begin{array}{l}\text { Proteus mirabilis } \\
\mathrm{N}(\%)\end{array}$ & $\begin{array}{l}\text { S.aureus } \\
\mathrm{N}(\%)\end{array}$ \\
\hline UBTH & 50 & $17(34.0)$ & $30(60.0)$ & $0(0.0)$ & $3(6.0)$ \\
NAUTH & 72 & $38(52.8)$ & $26(36.1)$ & $2(2.8)$ & $6(8.3)$ \\
p value & & 0.062 & 0.008 & 0.643 & 0.894 \\
\hline
\end{tabular}

$\mathrm{N}=$ Total number of clinical isolates; $\mathrm{P}=\mathrm{P}<0.05$ were considered significant

Table.3 Prevalence of multi-drug resistant isolates

\begin{tabular}{llllll}
\hline $\begin{array}{c}\text { Variable } \\
\text { Location }\end{array}$ & $\mathrm{N}$ & $\mathrm{N}(\%)$ & OR & $95 \% \mathrm{CI}$ & P Value \\
\hline UBTH & 50 & $39(78.0)$ & 0.982 & $0.492,2.106$ & 1.000 \\
NAUTH & 72 & $61(85.0)$ & 1.182 & $0.475,2.031$ & \\
\hline
\end{tabular}

$\mathrm{N}=$ Number of isolates; $\mathrm{P}=\mathrm{P}<0.05$ were considered significant; $\mathrm{N}(\%)=$ Percentage number of multidrug resistant isolate

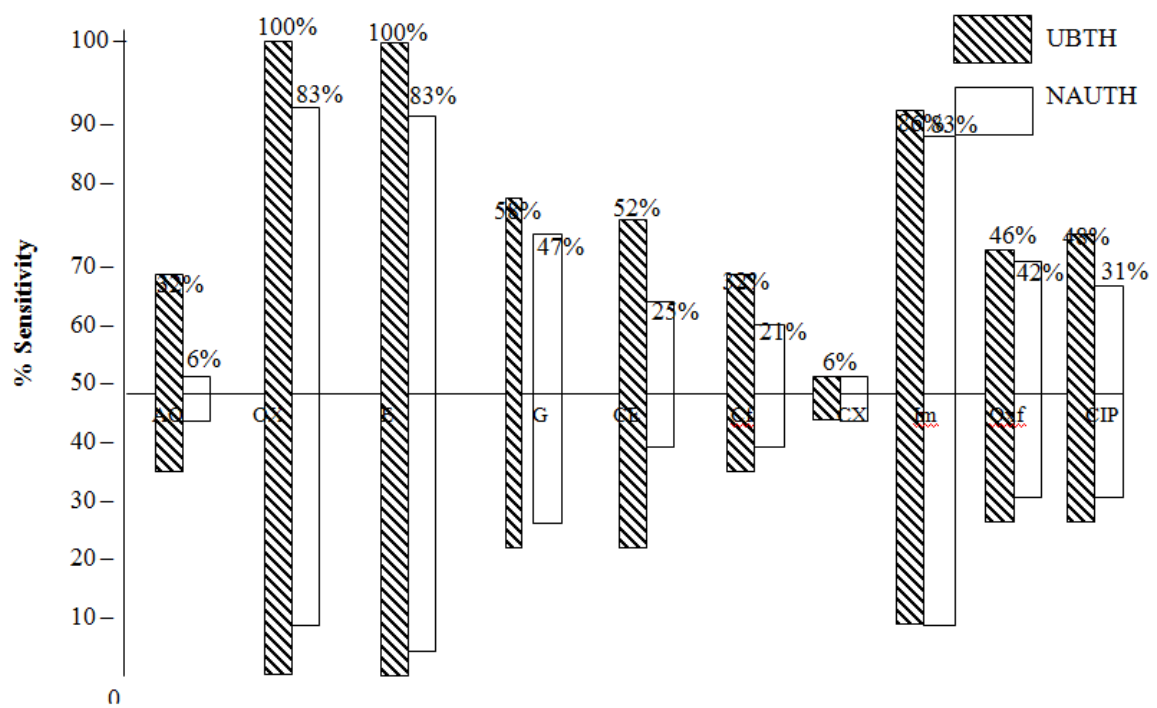

Fig.1 Antibiotic susceptibility profile of clinical isolates from UBTH and NAUTH AU $=$ Angnentin $(30 \mu \mathrm{g}), \mathrm{Ox}=$ Oxacillin $(1 \mu \mathrm{g}), \mathrm{E}=$ Enythromycin $(10 \mu \mathrm{g}), \mathrm{G}=$ gentamycin $(30 \mu \mathrm{g}), \mathrm{CE}=$ ceftazidime $(30 \mu \mathrm{g}), \mathrm{CF}=$ cefuroxime $(30 \mu \mathrm{g}), \mathrm{CX}=$ cefixime $(5 \mu \mathrm{g}), \mathrm{IM}=\mathrm{Imipenem}$ $(30 \mu \mathrm{g}), \mathrm{OXF}=\mathrm{Oxfloxacin}(5 \mu \mathrm{g})$ and $\mathrm{CIP}=$ ciprofloxacin $(5 \mu \mathrm{g})$ 


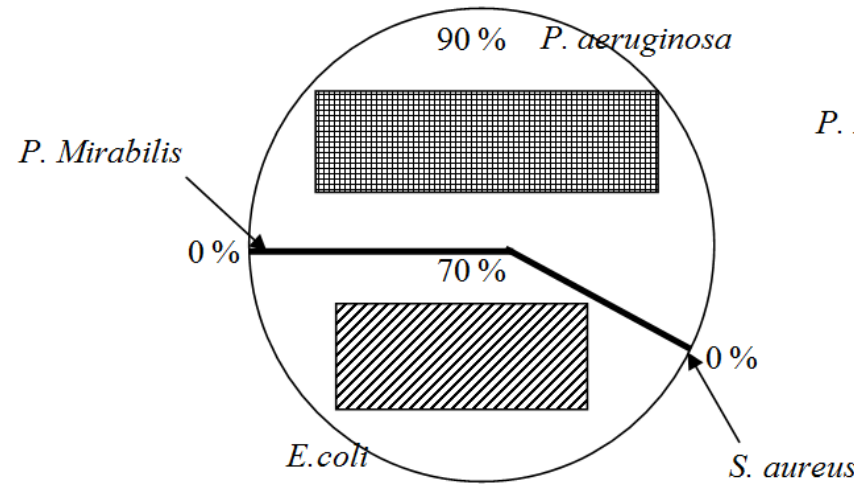

(UBTH)

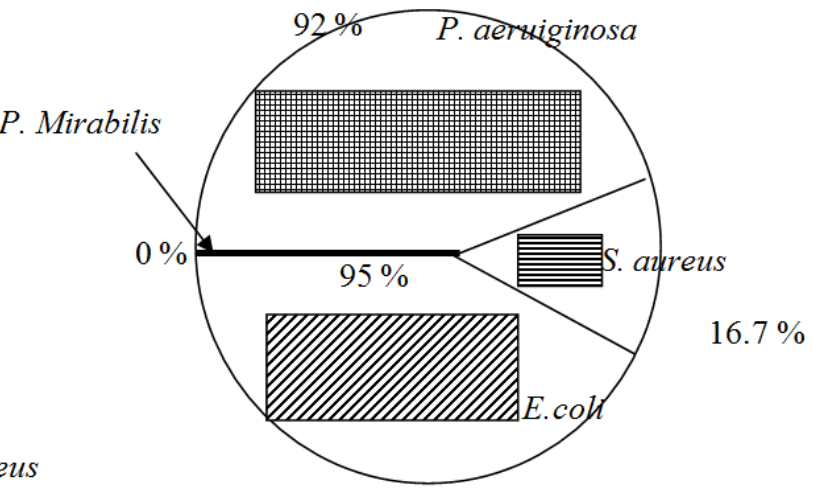

(NAUTH)

Fig.2 Percentage bacterial isolate from UBTH and NAUTH susceptible to antimicrobial agents

The variation in distribution of the isolates from the two locations with $E$. coli and $P$. aeruginosa ranking highest in distribution is in agreement with the works of Ezebialu et al. (2010) and Sulochana et al.( 2014) who found $P$. aeruginosa and $E$. coli to be more prevalent in surgical site infections, although other bacteria isolates such as $S$. aureus had predominated in some studies as reported by Aisha, et al.( 2013), Christopher et al. (2011) and Ojo et al. (2014). E. coli was found to be extremely predominant in hospital acquired infections worldwide making it the first nosocomial pathogen (Teresa et al., 1986).

There was a high resistance of the bacteria isolates from UBTH to Cefixime, Cefuroxime, Augmentin and Ofloxacin at 94\%, 68\%, 68\% and 54\%, while Imipenem, Erythromycin and Oxacillin were least resistance at $14 \%, 0 \%$ and $0 \%$ respectively. In NAUTH, the isolates displayed the same high percentage resistance to Augmentin and Cefixime (94\%) followed by Cefuroxime, $(79 \%)$ and Ceftazidime $(75 \%)$. Imipenem , Erythromycin and Oxacillin were least resistance (17\%). The high resistance the isolates showed to the various antimicrobial agents used in this study may in part be due to various factors such as inappropriate usage of antibiotics and drug resistance mechanism possessed by the bacterial isolates. Cephalosporins and Penicillins have been found to be highly resisted by surgical wound pathogens. In the works of (Eduardo et al., 2008; Yah et al., 2010) Ceftazidime and Augmentin were mostly resisted by surgical wound etiologic bacterial. This is most likely due to the presence of Cephalosporinase and Penicillinase enzymes which prevent the action of the Beta-lactam ring structure of the antibiotics (Livermore, 1995 and Fontana et al., 2000).

Here, $P$. aeruginosa $(90 \%)$ ranked highest in resistivity to antibiotics among UBTH isolates followed by $E$. coli $(70.6 \%)$ and $S$. aureus, (0\%) while in NAUTH, E. coli $(95 \%)$ displayed highest resistance capacity followed by $P$. aeruginosa $(92 \%)$ and $S$. aureus (16.7\%). There was a high preponderance of resistance by the isolates from the two locations to the antibiotics (UBTH $=78 \%$; NAUTH $=85 \%$ ) and this is largely due to the fact that bacterial isolates develop resistance by different mechanisms such as ability to modify the antibiotics target site, possession of efflux pumps, presence of inhibiting enzymes, acquisition of resistant plasmids and mutation of the drug receptor sites. 
In conclusion, the overuse and misuse of antimicrobials chemotherapy may provide selective pressure for the spread of MDR strains of bacterial isolates. Therefore, efforts to promote the appropriate use of antimicrobials are paramount to avoid therapeutic failure in both locations. Thus, it is kin interest to educate hospital staff on the importance of good hygiene in order to curtail epidemiological spread of these hazardous bacteria

\section{References}

Aisha, M., Gbonjubola, O.A., Yakubu, K.I. 2013. Incidence and Antibiotic Susceptibility Pattern of Bacterial Isolates from Wound Infections in a Tertiary Hospital in Nigeria. Trop. J. Pharmaceutical Res., 12 (4): 617-621.

Anaya, D.A., Dellinger, E.P. 2006. Challenges in the prevention of surgical site infections. Infect. Med., 23: 120-126.

Bauer, A.W., Kirby, W.M. and Sherris, J.C. 1979. Antibiotics susceptibility testing by a standardized single disk method. American J. Clin. Pathol., 45: 493-496.

Cheesbrough, M. 2000. District Laboratory Practice Manual in Tropical Countries, part 2 Cambridge University Press, New York. Pp. 178-179.

Christopher, A.E., Richard, O., Isaac, O.I., Samson, O. 2011. Microbiology of Wound Infections and its Associated Risk Factors among Patients of a Tertiary Hospital in Benin City, Nigeria. J. Res. Health Sci., 11(2): 109-113.

Clinical and Laboratory Standards Institute (CLSI). 2006. Performance standards for antimicrobial susceptibility testing; sixteen international supplements.

Cowan, S.T., Steel, K.S. 1993. Manual for the identification of Medical Bacteria. Cambridge University Press, London. Pp 986.

Dalhatu, A., Yunusa, U., Ahmad, S., Timothy, G., Jari, S., Musa, M. 2014. Bacterial Agents of Abdominal Surgical Site
Infections in General Hospital Funtua, Katsina State, North-Western Nigeria. $J$. Dent. Med. Sci., PP. 48 - 52

Eduardo, L., Airton D.F., Jonas, P., Pedro, A. 2008. Prevalence of bacterial resistance in surgical wound infections in peripheral arterial surgery. Journal Vascular Brasileiro. Vol 7. No. 3 http://dx.doi.org/10.1590/S167754492008000300009.

Enabulele, I.O.M., Yah, S.C., Yusuf, E.O., Eghafona, N.O 2006. Emerging quinolones resistant transfer genes among Gram-negative bacteria isolates, isolated from faeces of HIV/AIDS patients attending some clinics and Hospitals in the City of Benin, Edo State, Nigeria. Online J. Health and Allied Sci., 3: 3-4.

Ezebialu, C.U., Chukwura, E.I., Ezebialu, I.U. 2010. Bacterial pathogens associated with wound infections at national orthopaedic hospital. Enugu. Nigerian J. Microbiol., 24(1): 1987 - 1992.

Ezechi, O.C., Edet, A., Akinlade, H., GabOkafor, C.V., Herbertson, E. 2009. Incidence and risk factors for caesarean wound infection in Lagos Nigeria. $B M C$ Res. Notes, 2: 186-204.

Fontana, R., Cornaglia, G., Ligozzi, M., Mazzariol, A. 2000. The final goal: penicillin-binding proteins and the target of cephalosporins. Clinical Microbiol. Infect., 6(3): 34-40.

Heggars, J.P. 2003. Assessing and controlling wound infections. Cincinnati Plastic Surgery, 30: 25-35.

Lee, J.C., Kang, H.Y., Jeong, J.H., Seol, S.Y., Cho, D.T., Kim, J., Lee, Y.C. 2000. Antimicrobial resistance and integrons found in commensal $E$. coli isolated from healthy humans. J. Bacteriol. Virol., 36(3): $133-139$.

Livermore, D.M. 1995. Beta-lactamases in laboratory and clinical resistance. Clin. Microbiol. Rev., 8(4): 557-584.

ManGram, A.J, Horan, T.C., Pearson, M.L., Silver, L.C., Jarvis, W.R. 1999. Hospital infection Control Practice Advisory Committee. Guideline for prevention of 
surgical site infection. Infect. Control and Hospital Epidemiol., 20: 247 -278.

Masaadeh, H.A., Jaran, A.S. 2009. Incident of pseudomonas aeruginosa in postoperative wound infection. American J. Infect. Dis., 5(1): 1-6.

Mohammed, A., Adeshina, G.O., Ibrahim, Y.K.E. 2013. Retrospective incidence of wound infections and antibiotic sensitivity pattern: A study conducted at the Aminu Kano Teaching Hospital, Kano, Nigeria. Int. J. Med. Med. Sci., (55): 60-66.

National Committee for Clinical Laboratory Standards. 2003. Methods for disk diffusion: approved standard M2A8: performance standards for NCCLS antimicrobial disc susceptibility tests.

Nejad, S.B., Allegranzi, B., Syed, S.B., Ellis, B., Pettet, D. 2011.Health care associated infection in Africa: a systematic review. Bulletin of the World Health Organization.89:757-765.

Ojo, S.K.S., Sargin, B.O., Esumeh, F.I. 2014. Plasmid curing Analysis of Antibiotic Resistance Beta - Lactamase Producing Staphylococci from Wounds and Burns Patients. Pakistan J. Biol. Sci., 17(1): $130-133$.

Oni, A.A., Ewete, A., Gbaja, A.T., Folade, A.F., Mutiu, W.B., Adeyemo, D.A., Bakare, R.A. 2006. Nosocomial Infection: Surgical Site Infection in UCH Ibadan, Nigeria. Nigeria J. Surgical Res., 8(12): 19-23.

Prescott, L.M., Harley, J.P., Klein, D.A.
2008. Microbiology. $7^{\text {th }} \quad$ Edition. McGraw-Hill Companies, New York. Pp. 366-367.

Reiye, E.M., Berhe G.K., Muthupandian, S., Derbew, F.B., Araya, G.W. 2014. Aerobic bacteria in post surgical wound infections and pattern of their antimicrobial susceptibility in Ayder Teaching and Referral Hospital, Mekelle, Ethiopia, 7: 575.

Sule, A.M., Thanni, L., Sule Odu, A.O., Olusanya, O. 2002. Bacterial pathogens associated with infected wounds in Ogun State University Teaching Hospital, Sagamu, Nigeria. African J. Clin. Experimental Microbiol., 3: 13-16.

Tenover, F.C. 2006. Mechanisms of Antimicrobial Resistance in Bacteria. American J. Infect. Control, 34: 3-10.

Teresa, C., Horan, M.P.H., John, W., White, William, R., Jarvis, M.D.T., Grace, E.R.N., David, M.S.H., James, M., Hughes, M.D. 1986. Nosocomial Infection Surveillance: Hospital Infections ProGram Center for Infectious Diseases. Morbidity and Mortality Weekly Reports. 35(1):17-29

WHO. 2011. Bulletin of the World Health Organization; 89:757 - 765.

Yah, S.C., Eghafona, N.O., Oranusi, S., Abouo, A.M. 2010. Widespread plasmid resistance genes among Proteus species in diabetic wounds of patients in the Ahmadu Bello University Teaching Hospital (ABUTH) Zaria. African $J$. Biotechnol., 6: $1757-1762$.

\section{How to cite this article:}

Ehiaghe Joy, I., F.A. Eghiaghe, R.A.U. Nwobu and Nwiyi Paul, O. 2016. Prevalence and Multidrug Antimicrobial Susceptibility of Bacteria Isolates Obtained from Surgical Site in Nigeria. Int.J.Curr.Microbiol.App.Sci. 5(7): 708-715. doi: http://dx.doi.org/10.20546/ijcmas.2016.507.081 